\title{
A GAS-ACTUATED PROJECTILE LAUNCHER FOR HIGH-ENERGY IMPACT TESTING OF STRUCTURES
}

\author{
Damodar R. Ambur \\ Structural Mechanics Branch. \\ NASA Langley Research Center \\ Hampton, VA 23681-0001 \\ Navin Jaunky and Robin E. Lawson \\ Old Dominion University \\ Norfolk, VA 23529-0247 \\ Norman F. Knight, Jr. \\ MRJ Technology Solutions, Inc. \\ Yorktown, VA 23693-2619 \\ Karen H. Lyle \\ Vehicle Technology Center - ARL \\ NASA Langley Research Center \\ Hampton, VA 23681-2199
}

\footnotetext{
Presented at the AIAA/ASME/ASCE/AHS/ASC 40th Structures, Structural Dynamics, and Materials Conference
}

AIAA Paper No. 99-1385 


\title{
A GAS-ACTUATED PROJECTILE LAUNCHER FOR HIGH-ENERGY IMPACT TESTING OF STRUCTURES
}

\author{
Damodar R. Ambur* \\ NASA Langley Research Center \\ Hampton, VA 23681-0001 \\ Navin Jaunky ${ }^{\dagger}$ and Robin E. Lawson ${ }^{\ddagger}$ \\ Old Dominion University \\ Norfolk, VA 23529-0247 \\ Norman F. Knight, Jr. ${ }^{\S}$ \\ MR.J Technology Solutions \\ Fairfax, VA 22030-7305 \\ Karen H. Lyle \\ Vehicle Technology Center - ARL \\ NASA Langley Research Center \\ Hampton, VA 23681-0001
}

\begin{abstract}
A gas-actuated penetration device has been developed for high-energy impact testing of structures. The high-energy impact testing is for experimental simulation of uncontained engine failures. The non-linear transient finite element code LS-DYNA3D has been used in the numerical simulations of a titanium rectangular blade with an aluminum target plate. Threshold velocities for different combinations of pitch and yaw angles of the impactor were obtained for the impactor-target test configuration in the numerical simulations. Complete penetration of the target plate was also simulated numerically. Fi-

\footnotetext{
*Assistant Head, Structural Mechanics Branch. Associate Fellow AIAA.

${ }^{\dagger}$ Postdoctoral Research Associate, Department of Aerospace Engineering. Member AIAA.

$\ddagger$ Graduate Student, Dept. of Aerospace Engineering, Student Member AIAA.

${ }^{\S}$ Aerospace Systems Division. Associate Fellow AIAA.

I Aerospace Engineer, Structural Mechanics Branch.

${ }^{1}$ Copyright (C) 1999 by the American Institute of Aeronautics and Astronautics, Inc. No copyright is aserted in the United States under Title 17, U.S code. The U.S Goverment has a royalty-free license to exercise all rights under the copyright claimed herein for Government Purposes. All other rights are reserved by the copyright owner.
}

nally, limited comparison of analytical and experimental results is presented for complete penetration of the target by the impactor.

\section{INTRODUCTION}

The potential hazard resulting from an uncontained turbine engine failure has been a longterm concern of the Federal Aviation Administration (FAA), National Aeronautical and Space Administration (NASA), and the aircraft industry (e.g., Refs. [1]-[5]). For the purpose of airplane evaluations, the FAA defines an uncontained failure of a turbine engine as any failure which results in the escape of rotor fragments from the engine or Auxiliary Power Unit (APU) that could result in a hazard (Refs. [4] and [5]). A contained failure is one where no fragments are released through the engine nacelle structure; however fragments may be ejected from the engine air inlet or exhaust. Rotor failures that are of concern are those where released fragments have sufficient energy to create a hazard to the airplane and its passengers.

Accepting that the failures will continue to occur in service, attempts are made to contain all debris within a strengthened structure (e.g., see Refs. [6][9]). Design and test requirements are imposed on the 
engine nacelle to ensure some containment capability. Engine nacelle design and test requirements are covered in the United States Code of Federal Regulations, Title 14, Aeronautics and Space, Part 33, Airworthiness Standards; Aircraft Engines ([1]). Part 33 of the Federal Aviation Regulations (FAR) has always required the engine nacelle to be designed to contain damage resulting from rotor blade failure. The containment of failed rotor blades is a complex process which involves high energy, high speed interactions of numerous locally and remotely located engine components (such as failed blade, other blades, containment structure, adjacent cases, bearings, bearing supports, shafts, vanes and externally mounted components). Once failure begins, secondary events of a random nature may occur whose course cannot be precisely predicted (e.g., [4]).

Therefore, assuming that uncontained debris will continue to be generated, design considerations outlined in the AC 20-128A (e.g., [5]) provide guidelines for achieving the desired objective of minimizing the hazard to an airplane from uncontained rotor failure. These guidelines assume a rotor failure will occur and that analysis of the effects of this failure is necessary. The designs intend to make the aircraft invulnerable to the debris by such means as deflection, the judicious location of critical parts, hydraulic lines, and structure, suitable redundency where appropriate. Given that the damage is uncontained, developing an understanding of the impact event of the engine fragments or other parts of the structure is needed. FAA Advisory Circular AC 20-128A (e.g., [5]) provides specifications for fragment sizes to be used in the safety analysis models. The fragment size includes a single disc with blades fragment, that is, with one-third of blade height and one-third of the mass of the disc with blades, intermediate fragments with one-third of the disc with blades radius with a mass of $1 / 30$ th of the disc with blades, and small fragments (shrapnel) ranging in size up to a maximum dimension corresponding to the tip half of the blade airfoil.

Assuming that the large engine fragments released in the radial direction of the engine are contained by the engine containment structure, experimental studies and analytical simulations are still necessary to understand the effect of small engine fragments ejected from the engine air inlet or exhaust on the surrounding structures. Designing aircraft structures to either withstand this threat or to perform safely after the threat occurs requires an understanding of the response of structures subjected to high-energy impacts from these small engine fragments. Although some high-energy penetration work has been conducted related to the development of engine containment structures (e.g., Refs. [1]-[8]), there is very little reported research (e.g., Refs. [10]-[12]) on metallic and composite airframes when this type of high-energy threat occurs. The main objectives of the present paper are to discuss the development of a high-energy impact device capable of projecting small impactor plates that are representative of small engine fragments (0.6-lb weight), and to present results from numerical simulations. The analysis efforts presented in this paper address:

a. The threshold velocity for the impactor to penetrate the test specimen when impacted at normal incidence to the target.

b. The threshold velocities for no penetration when the impactor strikes the target at attitudes that are combinations of pitch, roll and yaw directions.

c. To compare the analysis results with preliminary target penetration test results.

\section{GAS-ACTUATED PENETRATION DEVICE}

A photograph of the gas-actuated penetration device is shown in Figure 1 (a). The pressure chamber is connected to the barrel of the device through a diaphragm chamber. When the pressure differential across the diaphragm reaches a predetermined value, the diaphragm ruptures and the gas propels a sabot located in the barrel. The sabot is a hollow cylindrical body made of a plastic material with a provision in it to hold an impactor plate. The sabot is guided as it travels along the barrel so that the impactor plate orientation is not altered significantly before it impacts the target test specimen. When the sabot reaches the end of the barrel, a splitter arrangement in the muffler assembly engages the sabot and releases the impactor plate which travels farther and impacts the target. A photograph of the test specimen mounted in a picture frame fixture in front of the barrel is shown in Fig. 1(b). The box surrounding the test specimen is used as an impactor containment structure and is filled with sand bags.

The specimen penetration device is designed such that the impactor plate located in the sabot is projected at the target with specified tolerances on its attitude. Since the device will be used for composite structures which have directional properties, these tolerances are necessary to ensure that the impactor contacts the target at a given orientation with respect to its material axis. The goals for the tolerances in pitch, roll, and yaw angles are 2 degrees 
which is consistent with the tolerance used in manufacturing laminated composite structures.

\section{NUMERICAL SIMULATION TOOLS}

Finite element simulations of structural problems involve pre-processing, analysis and postprocessing. For the impact and penetration simulations, the pre-processing step is performed using the $1 N$ GRID computer code (Ref. [13]). The analysis step involves the nonlinear transient dynamic response prediction for the dynamic behavior prior to impact, the nonlinear impact and penetration event itself, and the subsequent dynamic behavior. The LS-DYNA3D computer code (Refs. [14, 15]) has been used for the analyses here. Additional details are provided in Ref. [16].

Penetration of the target plate can be simulated in two ways depending on the modeling approach used for the target plate. Using the approach of tied nodes with failure, coincident nodes are generated in selected regions and then tied together with a constraint relation. In the LS-DYNA3D code, these tied nodes remain together until the volume-weighted effective plastic strain, averaged over all elements connected to the nodes in a given constraint, exceeds a specified value. This approach is refered to herein as the TNWF approach. Once this value is exceeded. all nodes in that constraint are released to simulate the initiation of a crack, fracture or penetration. In the second approach, called the element erosion approach. the finite element model is generated in the standard manner without requiring duplicate coincident nodes. Once the effective plastic strain in an element reaches a specified critical value, the element is removed from the computations. In this approach, elements do not or separate from the initial finite element model and, hence, tracking the rigid-body motion of these newly created fragments is not necessary. The LS-TAURUS computer corle (e.g.. Refs. $[14,15]$ ) is used for postprocessing.

\section{CONFIGURATION STUDIED AND MODELING.}

The target configuration considered in the present study is shown in Figure 2. This configuration is representative of the test setup shown in Figure 1 (b). An aluminum target plate is clamped between two steel frames and a titanium impactor may have pitch and yaw angles as shown in the figure. The material properties for aluminum, steel and titanium are given in Table 1. An elastic-plastic strain-hardening material model is used within LSDYNA3D (Material Type 3 of Refs. [14, 15]).
The frame that supports the aluminum target plate and impactor are modeled using 8-node solid elements while the target is modeled using 4-node Belytschko-Lin-Tsay shell elements. The node distribution in the $\mathrm{x}, \mathrm{y}, \mathrm{z}$ direction is shown in Figure 2 by numbers in parenthesis. The impactor has a node distribution of 9 by 4 by 16 in the $x, y$, and z directions respectively, or 576 nodes with 360 elements. Using the INGRID (Ref. [13]) preprocessor, the impactor is initially positioned at the center and $0.25 \mathrm{in}$. away from the target. The impactor may then be pitched or yawed by two degrees as required. When the impactor is pitched by two degrees, it has to be translated by $-0.1362 \mathrm{in}$. in the $\mathrm{y}$-direction. Similarly, when the impactor is yawed by two degrees it has to be translated by $-0.1362 \mathrm{in}$. in the z-direction. These translations are necessary since the impactor is moving along the its orientation as shown in Figure 2. The translations are computed based on the distance between the impactor and the target in the gas launcher-target arrangement. The velocity of the impactor is $V_{0} \cos \left(\alpha_{p}\right) \cos \left(\alpha_{y}\right)$ in the $\mathrm{x}$-direction, $-V_{0} \sin \left(\alpha_{p}\right)$ in the $\mathrm{y}$-direction and $-V_{0} \cos \left(\alpha_{p}\right) \sin \left(\alpha_{y}\right)$ in the $\mathrm{z}$-direction, where $\alpha_{p}$ and $\alpha_{y}$ are the pitch and yaw angles, respectively, and $V_{0}$ is the speed of the impactor. All of the nodes of the impactor are prescribed with these velocity components.

The area with the dashed-line boundary as shown in Figure 2 is herein refered to as the shellbreak area and consists of coincident nodes which are tied together with a constraint relation. This approach for penetration modeling of tied-nodes-withfailure (TNWF) is used to simulate penetration of the target by the impactor. In the LS-DYNA3D code (Refs.[14, 15]), these tied nodes remain together until the volume-weighted effective plastic strain, averaged over all elements connected to the coincident nodes in a given constraint, exceeds a specified value. The specified plastic strain value for aluminum is 0.2 which is the ultimate strain at failure.

According to Figure 2, the element size in the shell-break area is 0.05 -in. and 0.20 -in. in the $y$ direction and z-direction, respectively. The element size for the impactor is 0.07267 -in. and 0.33333 -in. in the $\mathrm{y}$-direction and $\mathrm{z}$-direction, respectively. More than four elements in the shell-break area span the thickness of the impactor. Therefore, the element size in the shell break area is $23 \%$ of the smallest dimension of the impactor contact surface. A highly refined model should have an element size in the contact region (or shell-break area) between $20 \%$ to $25 \%$ of the smallest dimension of the impactor contact surface based on the studies reported in Ref. [17]. Hence, 
the model described in Figure 2 is highly refined. The finite element model consists of 11,730 nodes, 1,896 solid elements, and 4,408, shell elements.

Contact or impact algorithms have always been an important capability in the DYNA3D family of codes. Contact may occur along surfaces of a single body undergoing large deformation, between two or more deformable bodies, or between a deformable body and a rigid barrier. In the present study, the sliding interface with friction and separation approach (LS-DYNA3D, Interface Type 3) is used to model the impact event between the impactor and target plate, and the friction coefficients are prescribed to be equal to zero. The bounding surface of the three-dimensional impactor is treated as the slave surface, and the target plate as the master surface.

The LS-DYNA3D code permits automatic examination of the finite element mesh and material properties in order to determine an appropriate time step size for numerical stability. This time step size is then automatically adjusted throughout the transient analysis to account for contact and local material and geometric nonlinearities.

\section{RESULTS AND DISCUSSION}

Analytical simulation results obtained using the LS-DYNA3D code are reported in this section for the target configuration described in Figure 2. The modeling features discussed in the previous section were used. The finite element studies are based on the assessment of the time variation of the axial velocity of the centroid of the impactor, the time variation of the contact force in the axial direction, and the maximum plastic strain on the target.

Results are presented for the following cases with different initial impactor velocity $\left(V_{0}\right)$ and different pitch $\left(\alpha_{p}\right)$ and yaw $\left(\alpha_{y}\right)$ angles of the impactor:

- Case 1: $V_{0}=5,400 \mathrm{in} / \mathrm{sec}(450 \mathrm{ft} / \mathrm{sec}), \alpha_{p}=0$ degrees, $\alpha_{y}=0$ degrees.

- Case 2: $V_{0}=3,000 \mathrm{in} / \mathrm{sec}(250 \mathrm{ft} / \mathrm{sec}), \alpha_{p}=0$ degrees, $\alpha_{y}=0$ degrees.

- Case 3: $V_{0}=3,000 \mathrm{in} / \mathrm{sec}(2,50 \mathrm{ft} / \mathrm{sec}), \alpha_{p}=0$ degrees, $\alpha_{y}=2$ degrees.

- Case 4: $V_{0}=2,640 \mathrm{in} / \mathrm{sec}(220 \mathrm{ft} / \mathrm{sec}), \alpha_{p}=2$ degrees, $\alpha_{y}=0$ degrees.

- Case 5: $V_{0}=2,760 \mathrm{in} / \mathrm{sec}(230 \mathrm{ft} / \mathrm{sec}), \alpha_{p}=2$ degrees, $\alpha_{y}=2$ degrees.

Case 1 is intended to simulate the penetration test with the aluminum target plate. The damage result from this analysis case are used to compare with the corresponding experimental results.

Analytical simulations for Case 2 through 5 were performed to determine the threshold velocity for penetration for the different pitch and yaw angle combinations. The threshold velocity is defined as the velocity above which the impactor will penetrate the target completely. The threshold velocity is an important quantity in selecting the initial impactor velocity for the gas launcher. The threshold velocity was determined by analyses to be the velocity for which the impactor rebounds from the target while creating partial perforation of the target or producing a maximum plastic strain that is marginally lower than the ultimate strain value of 0.2 for aluminum without penetration of the target.

\section{Simulation Parameters}

To insure that a simulation analyses using the LS-DYNA3D code is meaningful, the analyst needs to monitor the time step size, the ratio of the sliding interface energy to the initial or total energy, and the nodal velocities. Since an explicit time integration algorithm is used in this code which automatically adapts the time step size as the plasticity and damage develop in the elements, the time step size may be driven to nearly zero. A problem with the simulation occurs for such a case. Similarly, if the ratio of the sliding interface energy to the total energy (Max(SIE ( TE)) is larger than $10 \%$, then the sliding interface penalty factor (SIPF) has to be adjusted. A good goal is to keep this ratio to be under $10 \%$. A high ratio of the sliding interface energy to the total energy may lead to a simulation problem where nodal velocities take on out-of-range values (e.g., Not a Number values). To achieve these goals in simulation, multiple analyses with the current finite element model and possible finite element remodeling is necessary to validate the simulation results.

The sliding interface penalty factor (SIPF) and the time step scale factor (TSSF) are two parameters among others that affect the simulation results. The variation in simulation results for Case 5 for different SIPF values is shown in Table 2 . The value for TSSF is 0.6 for all analyses. This value for TSSF does not lead to spikes in the time variation of the impactor axial velocity. Hence TSSF $=0.6$ is an appropriate value for the impactor velocities considered in Table 2. This value is also appropriate for the impactor velocities considered in the other simulations.

It can be seen from Table 2, that there are no simulation problems with Analysis Number 1 and 2, but the $\operatorname{Max}(\mathrm{SIE} / \mathrm{TE}$ ) values are $33 \%$ and $12 \%$ respectively. For Analysis Number 3 and 4, although the $\operatorname{Max}(\mathrm{SIE} / \mathrm{TE})$ values are well below 10\%, there are simulation problems. Analysis Number 5 and 6 were carried out for a velocity of $230 \mathrm{ft} / \mathrm{sec}$ and although the $\operatorname{Max}(\mathrm{SIE} / \mathrm{TE}$ ) value is $4 \%$ for Analy- 
sis Number 5 , there is a simulation problem. The $\operatorname{Max}(\mathrm{SIE} / \mathrm{TE}$ ) value is $8.5 \%$ for Analysis Number 6 which is considered to be acceptable and there is no simulation problem. In Analysis Number 6, the impactor rebounds from the target while creating a maximum plastic strain of 0.1972 . Hence Analysis Number 6 is considered to provide meaningful results for the case when $a_{p}=\alpha_{y}=2$ degrees. Since the maximum plastic strain is 0.1972 for Analysis Number $6, V_{0}=230 \mathrm{ft} / \mathrm{sec}$ is considered close to the threshold velocity.

Simulation for other cases were investigated in a similar manner to (ase 5). The simulation parameters and results for (ases 1 through 5 are summarized in Table 3. Reference [1 $\bar{i}$ ] shows the effect of SIPF on the time variation of the total energy. Accordingly, there is a discontimuity in the total energy associated with the out-of-range velocities. The importance of simulation paraneters for velocities that are close to the threshold volority is also discussed in Ref. [17]. It can be seen from Table 3 that the Max(SIE / TE) value is less than $10 \%$ for the cases considered. No simulation problems occurred up to the analysis termination time. At the analysis termination time, the impactor is away from the target and there is no contact with the target at all.

\section{Simulation Results}

For Case 1. "hen the velocity of the impactor is $450 \mathrm{ft} / \mathrm{sec}$ and with \%ro pitch or roll, there is complete penetration of $1 \mathrm{l}$ ' target and the residual velocity of the impar wor is $334.7 \mathrm{ft} / \mathrm{sec}$. The impactor rebounds from thr. largen for Cases 2 through 5 with residual velocition of $-13.6,-99.5,-77.0$, and -89.8 $\mathrm{ft} / \mathrm{sec}$, respectively. For (ase 2, there is partial penetration of the t:aren. whereas for Cases 3, 4 and 5, there is no partial penetration. However, in Cases 4 and 5 , the masimum effective plastic strains are 0.1950 and $0.191-2$. r.n. ultimate strain valum of (1.2. Therefore, the initial velocities for ( $: 1 \mathrm{~m}, 1 \mathrm{aml} ;$ ) are considered close to the threshold velurit! fir lle pitch and yaw angles considered. The initial w..lurity for Case 3 is not close to the thresholl w.....l! for the yaw angle considered, since the maximum . flantive plastic strain is well below the ultimint. - Irimill of 0.2 .

The axial w. lin! histories for the centroid of the impactor for ( : :... I / hrough 5 are shown in Figure 3 and the axial num inl firce for the target for Cases 1 through 5 are shown in Figure 4 . The residual velocity for Case $1 \mathrm{in}$ pritive and indicates penetration, while for the onlur cases the residual velocities are negative indicating rehound from the target. The difference in the velocity history between Case 1 and the other cases is mainly due to the large difference in the velocity of the impactor which leads to penetration of the target. The differences between the axial velocity histories for Cases 2 through 5 are small due to the small differences in impactor velocity and pitch and yaw angles. The maximum value of the axial contact force for Case 1 is much greater than for the other cases. The duration of contact is much shorter than for other cases, since the impactor velocity for Case 1 is greater than for the other cases. The small differences in axial contact force histories for Cases 2 through 5 are due to differences in impactor velocities and pitch and yaw angles.

A close-up view of the target deformed geometry (at $\mathrm{t}=1 \mathrm{~ms}$ ) in the vicinity of the impact site for Case 1 is shown in Figure 5, where petaling at the backside of the target can be seen. A contour plot of the effective plastic strain results (at $t=1 \mathrm{~ms}$ ) for Case 1 is presented in Figure 6. A contour plot of the effective plastic strain results ( $t=1.8 \mathrm{~ms}$ ) for Case 2 is presented in Figure 7, which shows the partial penetration of the target.

A test was conducted with an impactor axial velocity of $450 \mathrm{ft} / \mathrm{sec}$, and the impactor penetrated the aluminum target. On examining the damaged target, it was observed that the impactor made contact with the target below the center of the target. This observation suggests that the impactor had a different pitch angle. The exact pitch angle is difficult to assess since some test conditions were unknown. A photograph of the region around the impact site of the test target is shown in Figure 8. When comparing Figure 8 with Figure 5 , it can be seen that the deformed geometry for Case 1 (Figure 5), which has zero pitch and yaw angles, has less petaling on one side of the impact site in Figure 5 than in Figure 8. The difference in damage shown in Figure 8 may be due to the impactor having a pitch angle which is not small. Also comparing the simulation results for Cases 2 and 4 , it can be seen that a two-degree pitch angle in Case 4 led to a decrease from $250 \mathrm{ft} / \mathrm{sec}$ (threshold velocity for Case 2 ) to $230 \mathrm{ft} / \mathrm{sec}$ (threshold velocity for Case 4 ) or a $12 \%$ decrease in threshold velocity between Cases 2 and 4 . This obsevation suggests that the test configuration is sensitive to even small pitch angles for the impactor.

\section{CONCLUDING REMARKS}

A gas-actuated penetration device has been developed for high-energy impact testing of structures. High-energy impact tests were conducted to determine the threshold velocities for complete penetration of the target plate by a rectangular titanium plate impactor. Threshold velocities for different 
combinations of pitch and yaw angles of the impactor were obtained for the impactor-target test configuration in the numerical simulations. The numerical simulation results indicate that the threshold velocity is sensitive to small pitch and yaw angles of the impactor. A pitch angle of the impactor decreases the threshold velocity compared to the threshold velocity for zero pitch and zero yaw angle of the impactor. A yaw angle of the impactor increases the threshold velocity compared to the threshold velocity for zero pitch and zero yaw angle of the impactor. Numerical simulation predicted damage similar to that obtained from an experiment for complete penetration of the target by the impactor.

\section{References}

[1] Witmer, E. A. (Editor), An Assessment of Technology for Turbojet Engine Rotor Failures, Proceedings of a workshop sponsored by NASA Lewis Research Center and held at MIT on March 29-31, 1977, NASA CP-2017, August 1977.

[2] Gerstle, J. H., "Analysis of Rotor Fragment Impact on Nallistic Fabric Engine Burst Containment Shields," Journal of Aircraft, Vol. 12, No. 4. April 1975, pp. 388-393.

[3] Sarkar, S., and Atluri, S. N., "Impact Analysis of Rotor Fragments on Aircraft Engine Containment Structures," Structural Integrity in Aging Aircraft, C. I. Chang and C. T. Sun (editors), ASME, AD-Vol. 47, 1995, pp. 87-97.

[4] Anon., "Turbine Engine Rotor Blade Containment/Durability," Federal Aviation Administration Advisory Circular No. 33-5, June 18, 1990.

[5] Anon., "Design Considerations for Minimizing Hazards Caused by Uncontained Turbine Engine and Auxiliary Power Unit Rotor Failure," Federal Aviation Administration Advisory Circular No. 20-128A, March 25, 1997.

[6] Le, D. D., Evaluation of Lightweight Material Concepts for Aircraft Turbine Engine Rotor Failure Protection, Federal Aviation Administration Report No. DOT/FAA/AR-96/110, July 1997.

[7] Mathis, J. A., Design Procedures and Analysis of Turbine Rotor Fragment Hazard Containment, Federal Aviation Administration Report No. DOT/FAA/AR-96/121, March 1997.
[8] Shockey, D. A., Giovanola, J. H., Simons, J. W., Erlich, D. C., Klopp, R. W., and Skaggs, S. R., Advanced Armor Technology: Application Potential for Engine Fragment Barriers for Commercial Aircraft, Federal Aviation Administration Report No. DOT/FAA/AR-97/53, September 1997.

[9] Emmerling, William, Presentation Charts from the Third FAA Workshop on Uncontained Engine Debris Characterization, Mitigation and Modeling, held in San Diego, CA, October 2830, 1997 .

[10] Zukas, J. A., Jones, G. H., Kimsey, K. D., Misey, J. J., and Sherrick,T. M., "Three-Dimensional Impact Simulations: Resources and Results," Computer Analysis of Large-Scale Structures, $\mathrm{K}$. C. Park and R. F. Jones, Jr. (editors), ASME, AMD-Vol. 49, 1981, pp. 35-68.

[11] Whirley, Robert G., "Elasto-plastic Shell Analysis in DYNA3D," Mechanical Engineering, ASME, Vol. 113, No. 1, January 1991, pp. 5660.

[12] Dietz, D., "FEA Makes Airframes Safer," Mechanical engineering, ASME, Vol. 120, No. 1, January 1998, pp. 64-65.

[13] Stillman, D. W., and Hallquist, J. O., "INGRID: A Three-Dimensional Mesh Generator for Modeling Nonlinear Systems," University of California, Lawrence Livermore National Laboratory, Report UCID-20506, 1985.

[14] Anon., LS-DYNA3D User's Manual, Livermore Software Technology Corporation May 1, 1995.

[15] Anon., LS-DYNA3D Theoretical Manual, Livermore Software Technology Corporation.

[16] Lawson, Robin E., "LS-DYNA3D Modeling and Simulation for Uncontained Engine Debris Impact on Fuselage Skins," Master's Thesis, Department of Aerospace Engineering, Old Dominion University, Norfolk, VA, May 1999.

[17] Knight, N. F., Jaunky, N., Lawson, R. E., and Ambur, D. A., "Modeling and Simulation for Uncontained Engine Debris Impact on Fuselage Skins using LS-DYNA3D.," presented at AIAA/ASME/ASCE/AHS/ASC $40^{\text {th }}$ Structures, Structural Dynamics, and Materials Conference, April 12-15, 1999, St. Louis, MO, AIAACP Paper No. 99-1573. 
Table 1 Material properties for aluminum, titanium, and steel.

\begin{tabular}{lccc}
\hline \hline & $\begin{array}{c}\text { Aluminum } \\
(2024-\mathrm{T} 3)\end{array}$ & $\begin{array}{c}\text { Titanium } \\
(\mathrm{Ti}-6 \mathrm{Al}-4 \mathrm{~V})\end{array}$ & $\begin{array}{c}\text { Steel } \\
(\mathrm{A} 36)\end{array}$ \\
\hline Young's modulus (Msi) & 10.0 & 16.0 & 30.0 \\
Poisson's ratio & 0.30 & 0.30 & 0.30 \\
Yield strength (Msi) & 0.05 & 0.12 & 0.35 \\
Tangent modulus (Msi) & 0.10 & 0.30 & 0.15 \\
Hardening parameter & 0.20 & 0.20 & 0.23 \\
Weight density (lbs/in ${ }^{3}$ ) & 0.10 & 0.16 & 0.28 \\
Ultimate strain to failure (in/in) & 0.20 & - & - \\
\hline \hline
\end{tabular}

Table 2 Effect of SIPF on numerical simulation results for Case 5.

\begin{tabular}{|c|c|c|c|c|c|}
\hline $\begin{array}{l}\text { Analysis } \\
\text { No. }\end{array}$ & $\begin{array}{l}\text { Initial velocity, } \\
V_{0}, \mathrm{ft} / \mathrm{sec}\end{array}$ & $\mathrm{SIPF}^{a}$ & $\mathrm{TSSF}^{b}$ & $\operatorname{Max}(\mathrm{SIE} / \mathrm{TE})^{c}$ & $\begin{array}{c}\text { Termination } \\
\text { time, } \mathrm{ms}\end{array}$ \\
\hline \multirow[t]{2}{*}{1} & 250 & $0.25 \mathrm{E}-03$ & 0.60 & $33 \%$ & 1.8 \\
\hline & Remark: Maxin & um effective & plastic & train is $0.152, \mathrm{imp}$ & ctor rebound. \\
\hline \multirow[t]{2}{*}{2} & 250 & $0.35 \mathrm{E}-03$ & 0.60 & $12 \%$ & 1.8 \\
\hline & Remark: Maxim & um effective & plastic & train is 0.187 , imp & ctor rebound. \\
\hline \multirow[t]{2}{*}{3} & 250 & $0.55 \mathrm{E}-03$ & 0.60 & $4.8 \%$ & 1.8 \\
\hline & Remark: Target & plate penet & ation a & d out-of-range velc & ities at $1.5 \mathrm{~ms}$. \\
\hline \multirow[t]{2}{*}{4} & 250 & $0.45 \mathrm{E}-03$ & 0.60 & $6.1 \%$ & 1.8 \\
\hline & Remark: Target & plate penet & ation a & d time step size $\mathrm{dr}$ & ren to zero at $\mathrm{t}=1.317 \mathrm{~ms}$. \\
\hline \multirow[t]{2}{*}{5} & 230 & $0.45 \mathrm{E}-03$ & 0.60 & $4 \%$ & 1.8 \\
\hline & Remark: Target & plate perfo & ation al & d impactor reboun & Out-of-range velocities at $1.14 \mathrm{~ms}$ \\
\hline \multirow[t]{2}{*}{6} & 230 & $0.35 \mathrm{E}-03$ & 0.60 & $8.5 \%$ & 1.9 \\
\hline & Remark: Maxin & um effectiv & plastic & train is 0.1972 and & impactor rebound. \\
\hline
\end{tabular}

Table 3 Summary of simulation parameters and results for Cases 1 through 5 .

\begin{tabular}{llllll}
\hline \hline Case No. & 1 & 2 & 3 & 4 & 5 \\
\hline Initial velocity, $V_{0}(\mathrm{ft} / \mathrm{sec})$ & 450 & 250 & 250 & 220 & 230 \\
$\left(\alpha_{p}, \alpha_{y}\right)$ degree & $(0,0)$ & $(0,0)$ & $(0,2)$ & $(2,0)$ & $(2,2)$ \\
Termination time (ms) & 1.0 & 1.8 & 1.8 & 1.8 & 1.9 \\
& & & & & \\
SIPF & $0.5 \mathrm{E}-03$ & $0.75 \mathrm{E}-03$ & $0.25 \mathrm{E}-03$ & $0.65 \mathrm{E}-03$ & $0.35 \mathrm{E}-03$ \\
TSSF & 0.6 & 0.6 & 0.6 & 0.6 & 0.6 \\
Max(SIE / TE) \% & 1.0 & 2.2 & 2.2 & 6.0 & 8.5 \\
& & & & & \\
Residual velocity (ft/sec) & 334.7 & -43.6 & -99.5 & -77.0 & -89.8 \\
$\begin{array}{l}\text { (axial direction) } \\
\text { Maximum plastic strain }\end{array}$ & 0.2000 & 0.2000 & 0.1460 & 0.1950 & 0.1972 \\
Target penetration & Complete & partial & NO & NO & NO \\
Impactor rebound & NO & YES & YES & YES & YES \\
& & & & & \\
Number of cycles & 8308 & 14954 & 14954 & 14954 & 15785 \\
CPU* time (sec) & 4591 & 8104 & 8272 & 8210 & 8421 \\
\hline \hline
\end{tabular}

${ }^{*} \mathrm{CPU}$ time is for SGI Indigo R4400 machine 


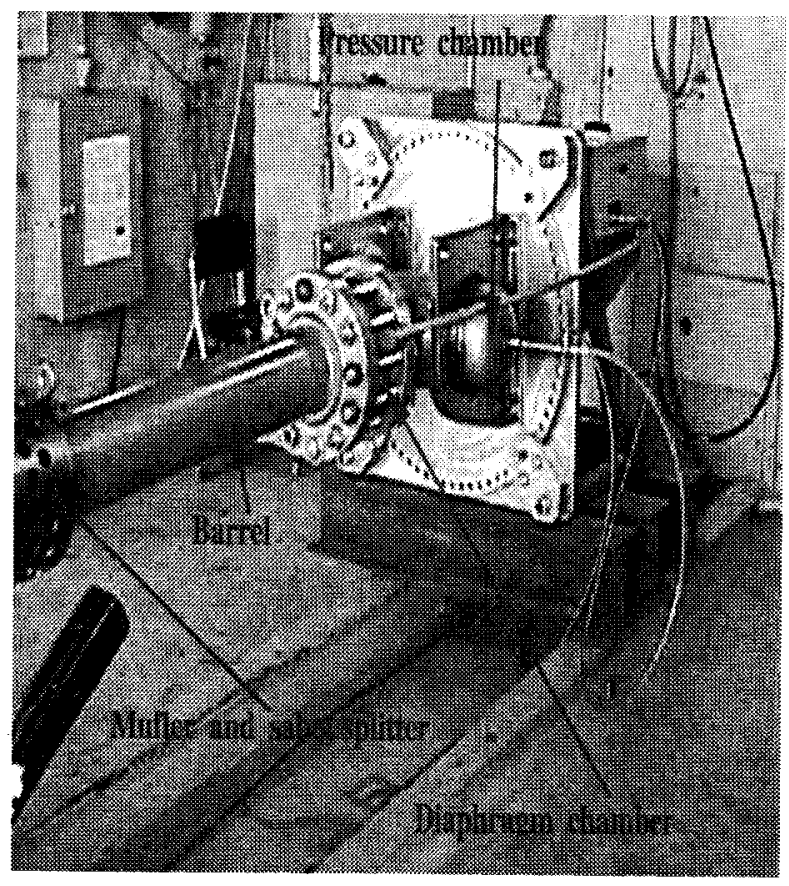

(a) Projectile launcher

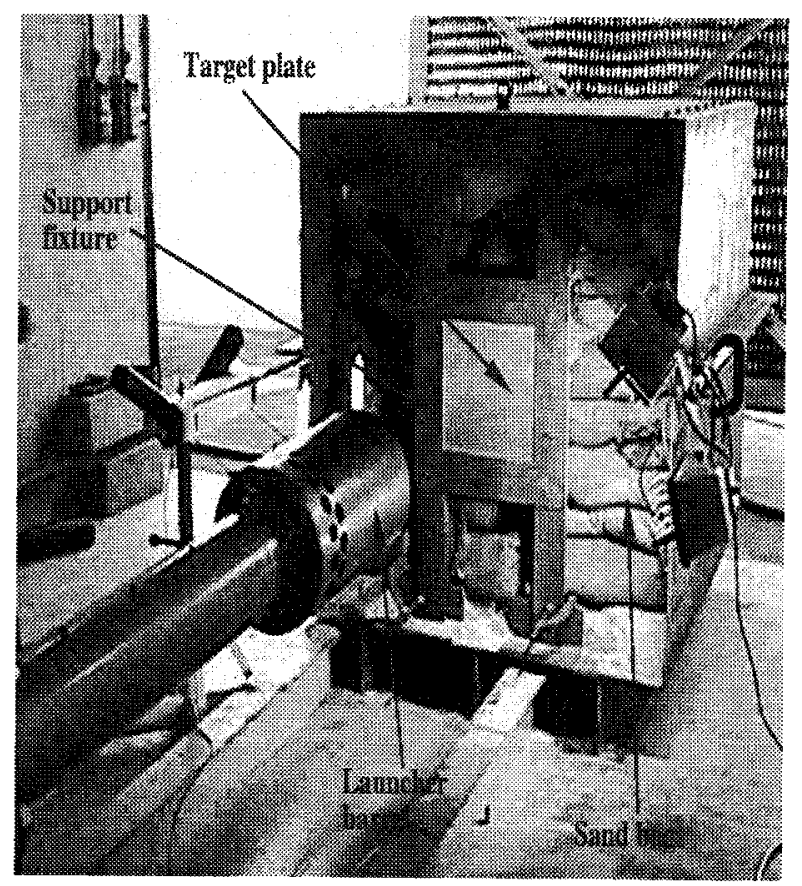

(b) Target plate assembly

Figure 1: Photograph of the gas-actuated projectile launcher and test setup.

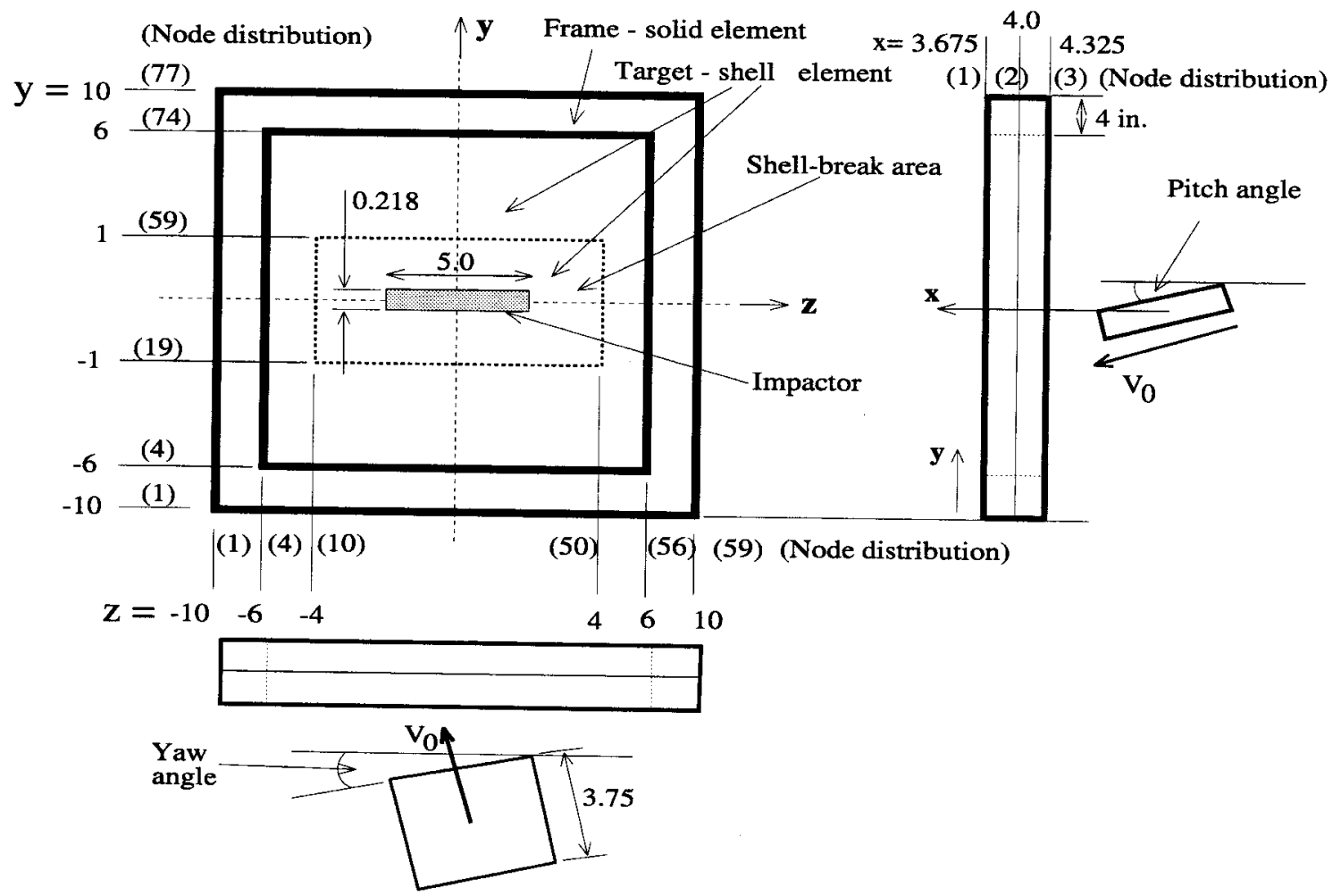

Figure 2: Dimensions and finite element node distribution for the test configuration. (Not to scale. All dimensions in inches.) 


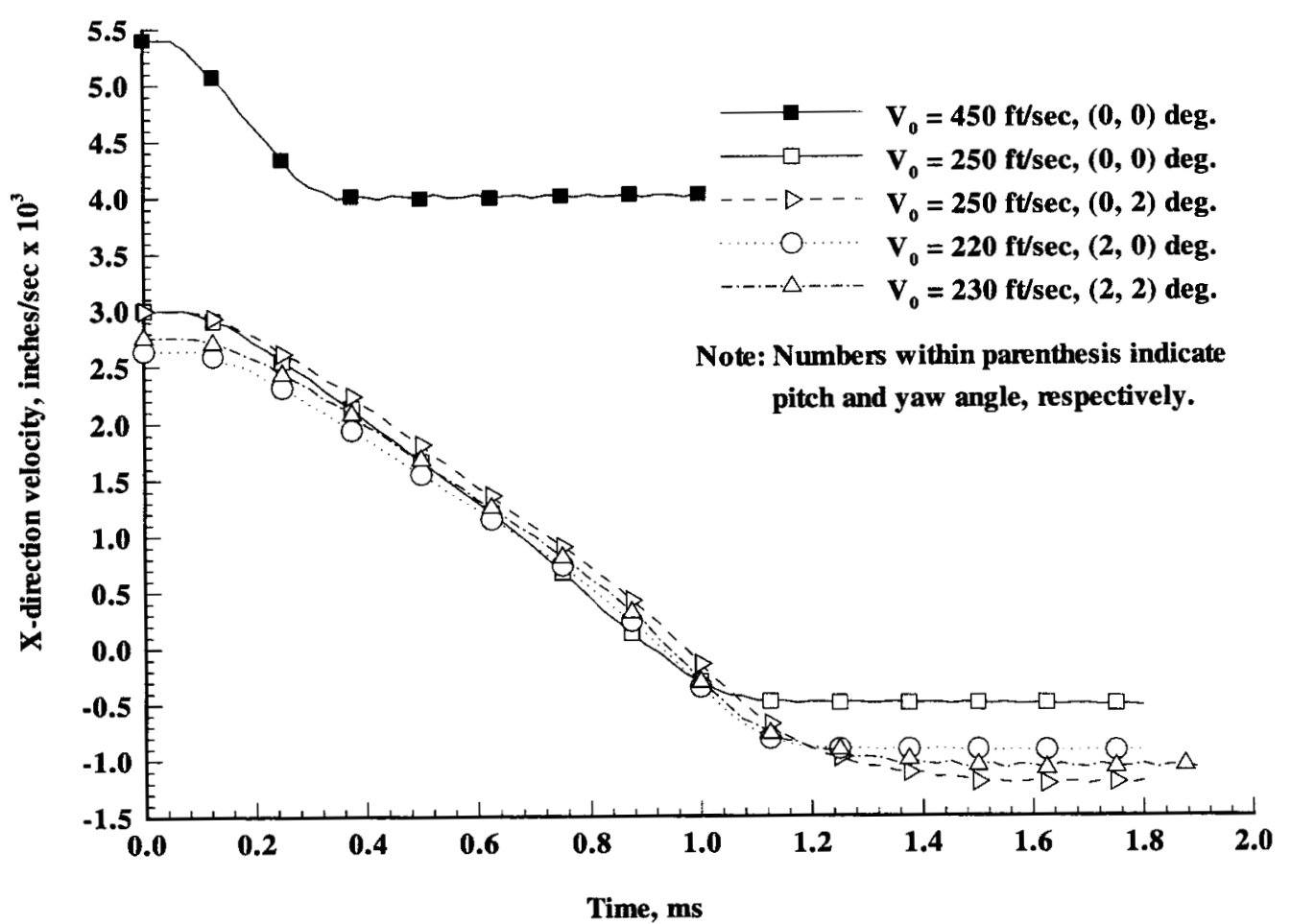

Figure 3: Axial velocity history of impactor for simulation Cases 1 through 5 .

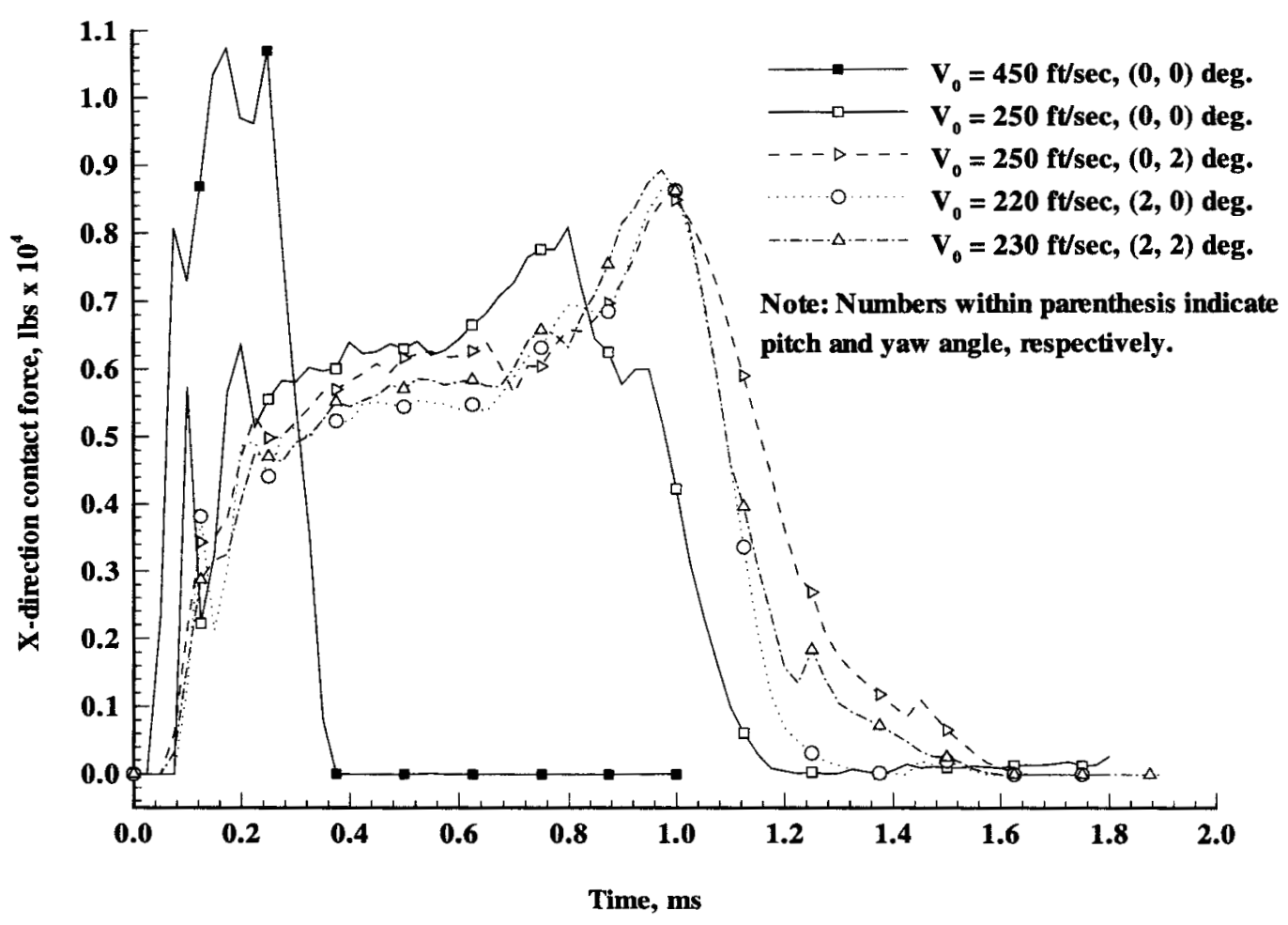

Figure 4: Axial contact force history of target for simulation Cases 1 through 5 . 


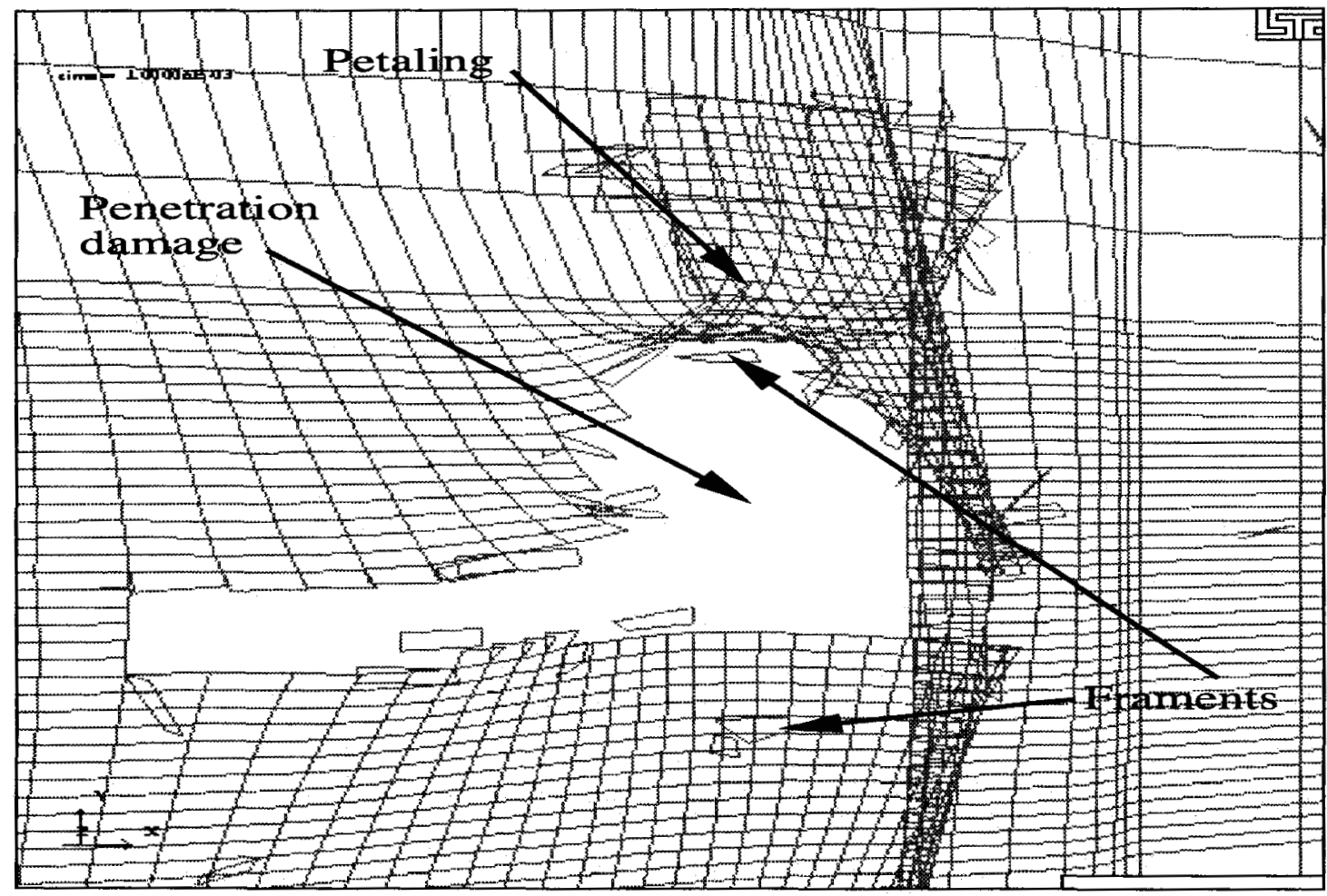

Figure 5: Deformed geometry of target in the vicinity of the impact site for simulation Case 1 at $t=1 \mathrm{~ms}$.

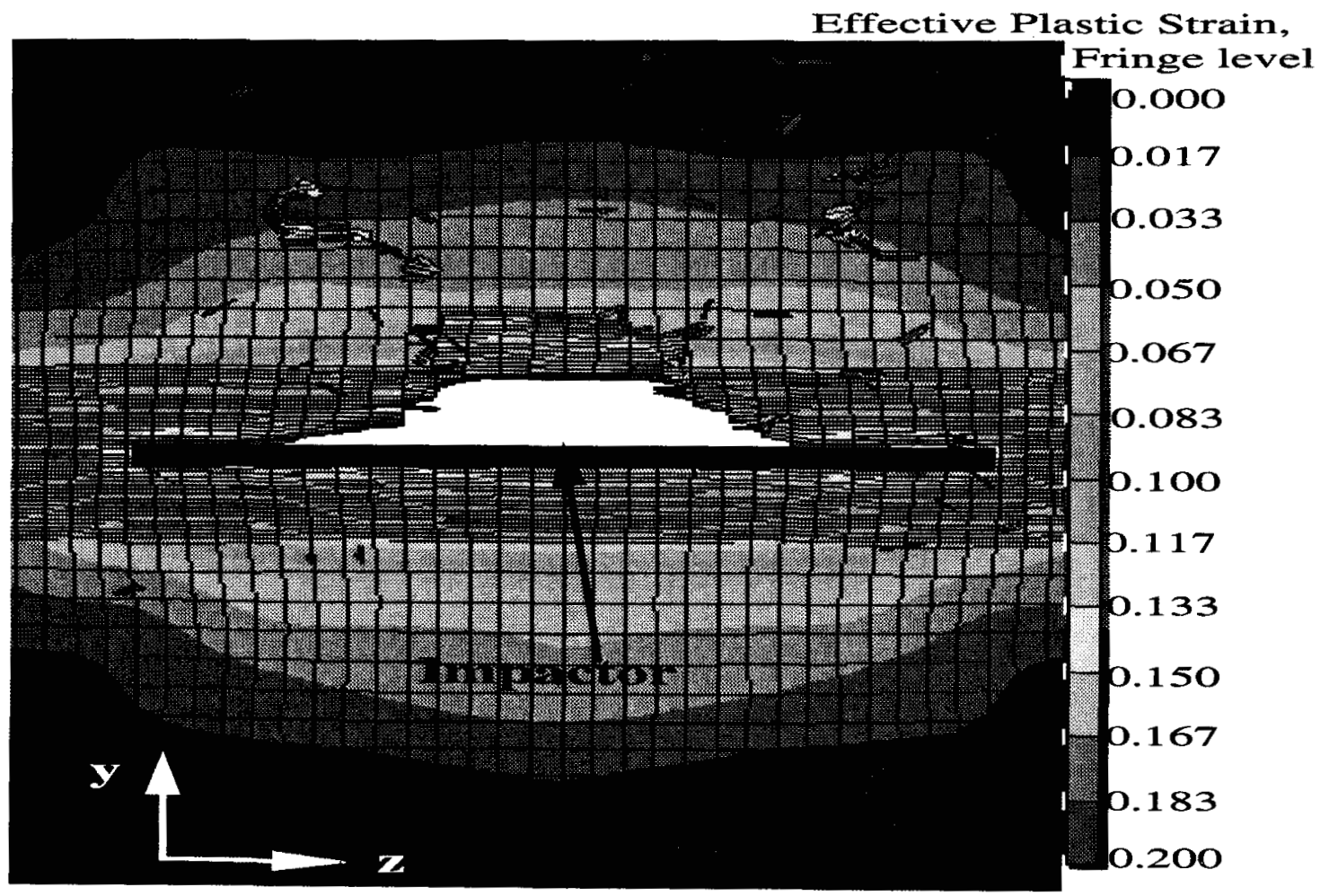

Figure 6: Contour plot of effective plastic strain for simulation Case 1 at $\mathrm{t}=1 \mathrm{~ms}$. 
Effective Plastic Strain,

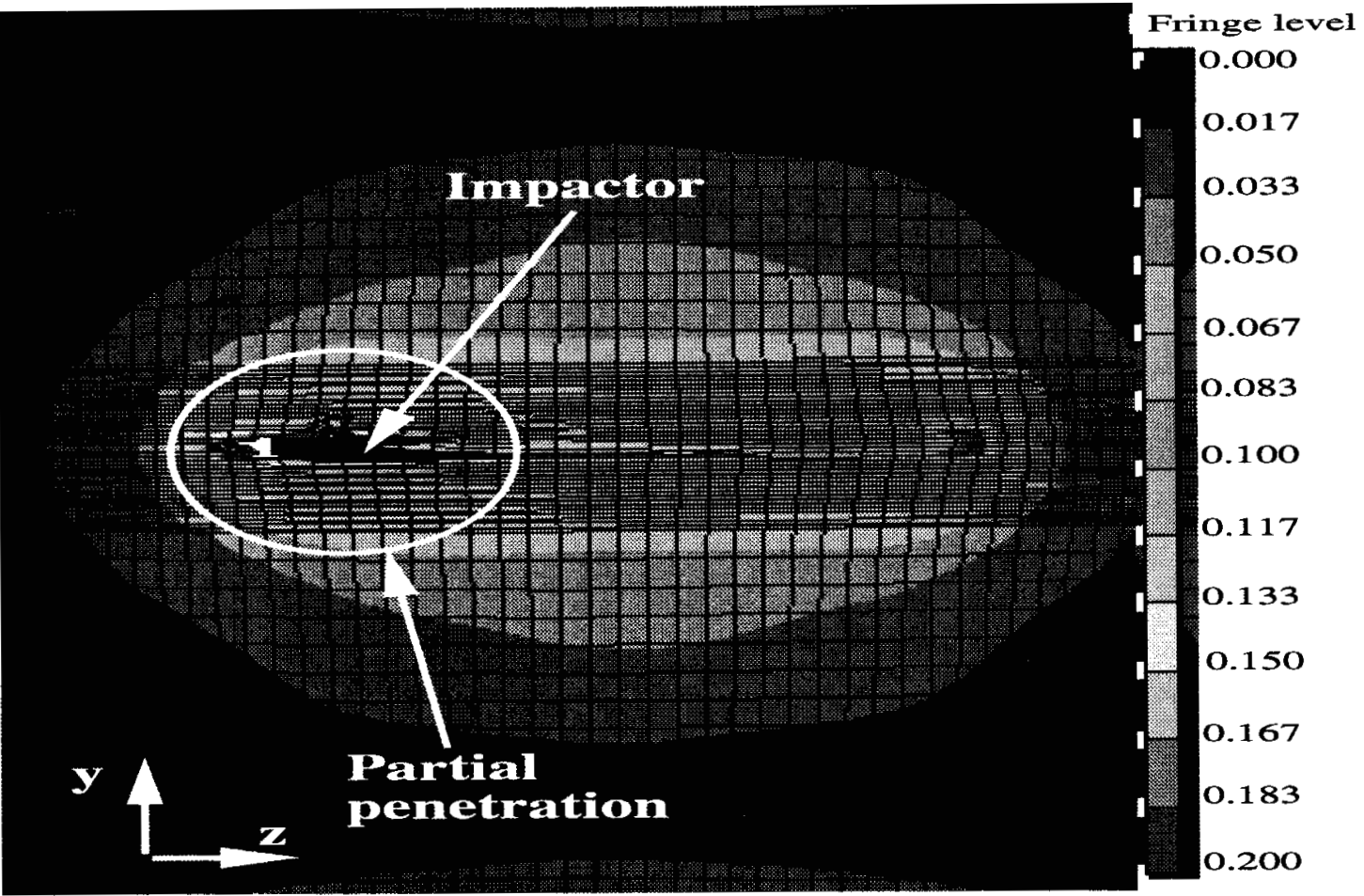

Figure 7 : ('ontour plot of effective plastic strain for simulation Case 2 at $\mathrm{t}=1.8 \mathrm{~ms}$.

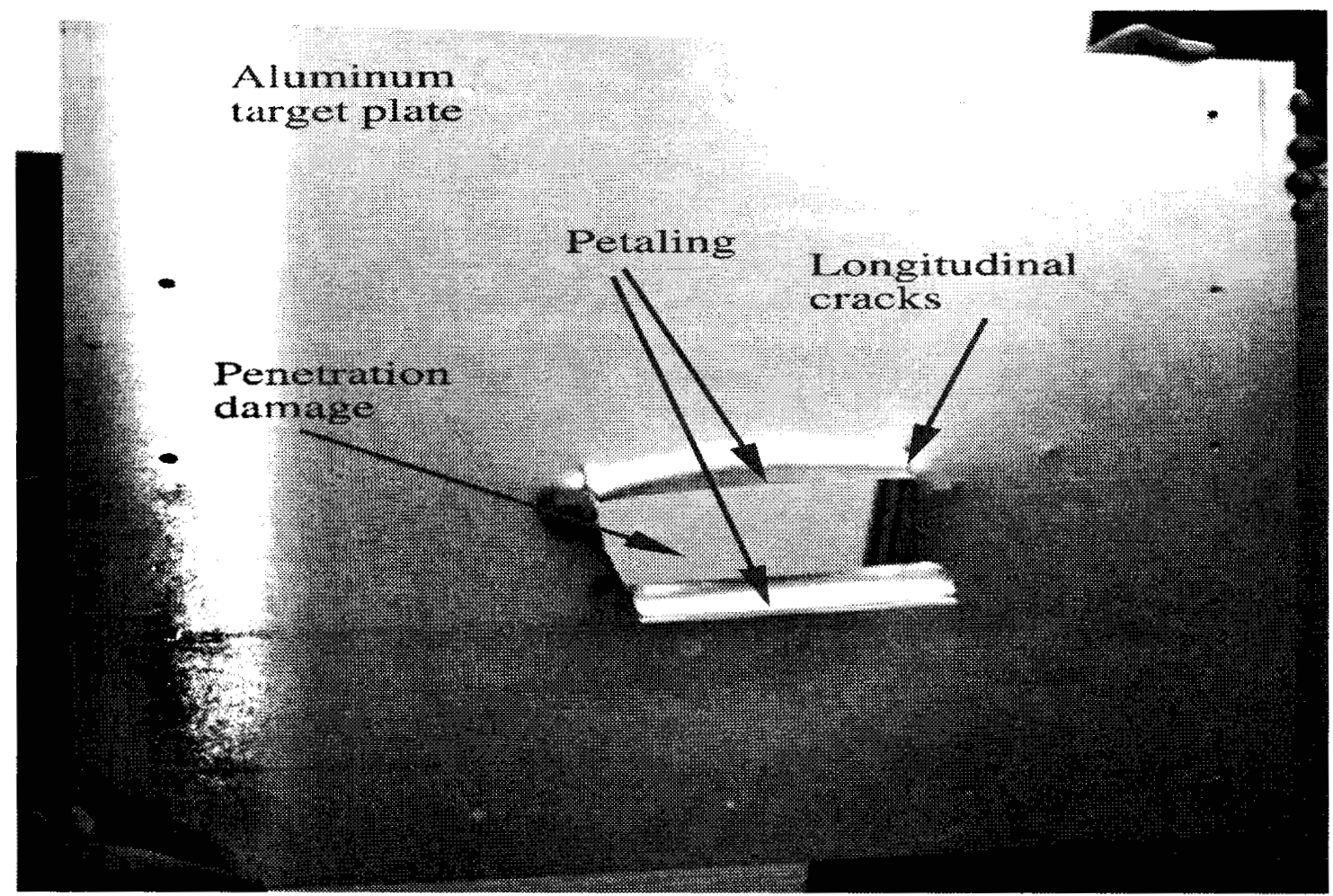

Figure $\delta$ : Photugraph of damage aluminum target for an impactor initial velocity of $450 \mathrm{ft} / \mathrm{sec}$. 